\title{
Liver Resection and Transplantation in Hepatocellular Carcinoma
}

\author{
J. Belghiti D. Fuks
}

Department of HPB Surgery and Transplantation, Beaujon Hospital (Assistance Publique Hôpitaux de Paris), University Paris 7 Denis Diderot, Clichy, France

\section{Key Words}

Cirrhosis · Hepatocellular Carcinoma - Liver resection - Liver transplantation · Recurrence

\begin{abstract}
Liver resection is the most available, efficient treatment for patients with hepatocellular carcinoma. Better liver function assessment, increased understanding of segmental liver anatomy using more accurate imaging studies, and surgical technical progress are the most important factors that have led to reduced mortality, with an expected 5 year survival of $70 \%$. Impairment of liver function and the risk of tumor recurrence lead to consideration of liver transplantation (LT) as the ideal treatment for removal of the existing tumor and the preneoplastic underlying liver tissue. However, LT, which is not available in many countries, is restricted to patients with minimum risk of tumor recurrence under immunosuppression. Limited availability of grafts as well as the risk and the cost of the LT procedure has led to considerable interest in combined treatment involving resection and LT. An increasing amount of evidence has shown that initial liver resection in transplantable patients with a single limited tumor and good liver function is a valid indication. Histological analysis of specimens allows identification of the subgroup of patients who could benefit from follow-up with LT in case of recurrence.

Copyright @ 2012 S. Karger AG, Basel
\end{abstract}

\section{Introduction}

Hepatocellular carcinoma (HCC) is the sixth most common cancer, third most common cause of cancer death, and the most common primary malignancy of the liver [1]. HCC development is associated with the occurrence of chronic liver disease (CLD) due to chronic 
viral infection, alcohol consumption, hemochromatosis, and metabolic syndrome, and often with a combination of two of these factors. The underlying liver parenchyma is rarely normal and displays various histological changes, including steatosis, inflammation, and progressive degrees of fibrosis leading to cirrhosis. These histological changes of the underlying parenchyma and the frequent multiplicity of tumors limit the possibility of curative treatments, which include local ablation of small and isolated tumors, partial liver resection (LR), and liver transplantation (LT) [2]. Although less than 30\% of patients with HCC are eligible for surgery, this treatment remains the most available, efficient treatment for these patients [3-5]. Considerable progress observed during the last 10 years in screening, treatment of the underlying liver disease, early radiological diagnosis, and surgical techniques has updated the indications for surgical treatment for HCC [2]. Better liver function assessment, understanding of segmental liver anatomy using more accurate imaging studies, and surgical technical progress are the most important factors that have led to reduced mortality, with an expected 5 year survival of 70\% [6]. Impairment of liver function and the risk of tumor recurrence lead to consideration of LT as the ideal treatment for removal of existing tumors and preneoplastic underlying liver. However, LT, which is not available in many countries, is restricted to patients in good general condition with minimum risk of tumor recurrence under immunosuppression [7]. Limited availability of grafts as well as the risk and the cost of the LT procedure induce considerable interest in combined treatment involving resection and LT $[7,8]$.

We Hereby Present Current Evidence Regarding the Roles of Resection and LT in The Management of HCC.

\section{Partial Liver Resection}

In patients with HCC, both tumor extension and degree of histological change of the underlying parenchyma considerably influence the indication for and extent of partial LR. Major histological changes observed in patients with HCC include fibrosis ranging from mild (F1) to cirrhosis (F4). Although some authors combine F3 with F4, there are several arguments for a classification that separates F3 and F4, with the latter constituting cirrhosis having a lower rate of regeneration, more frequent association with portal hypertension, higher risk of tumor multiplicity, and therefore, higher risk of recurrence [8-10]. Absence of extensive fibrosis or cirrhosis does not put the patient at low risk because the conjunction of steatosis and the inflammatory process has an important role in the tolerance of resection. Partial LR in diseased parenchyma presents risk due to altered texture of the liver parenchyma, impaired liver regeneration, and deteriorated liver function, leading to coagulation defects and an increased risk of infection [11]. In the setting of diseased parenchyma, there exists a close relationship between the extent of resection and postoperative risk that limits the indication of resection in patients with large tumors [12]. Indeed, partial LR in patients with a diseased liver must follow the following two contradictory objectives: to be curative with resection of the tumor vascular territories and to preserve as much liver parenchyma volume as possible to prevent postoperative liver failure.

\section{Morphological Assessment}

Small liver remnant volume is associated with worse postoperative liver function and a higher complication rate after extended hepatectomy [13]. Although the safety limit for the 
remnant liver volume in patients with normal liver is approximately $30 \%$ of the total nontumorous or functional liver volume, the required volume is much higher in patients with CLD. The safety limit depends on the severity of cirrhosis, which influences the regeneration capacity of the diseased parenchyma. In general, in patients with CLD, a remnant liver volume of $40-50 \%$ of the total liver volume should be preserved after major LR. There are strong arguments against patients with either one of these criteria undergoing major LR without preoperative volume modulation induced by preoperative portal vein embolization (PVE). However, the degree of hypertrophy of the future liver remnant (FLR) after PVE is variable in patients with CLD $[13,14]$. It is generally accepted that the absence of early hypertrophy of a nonembolized liver following technically successful PVE is an indicator of absence of or low regenerative capacity that would contraindicate surgery, and thus, represents a real dynamic stress test before major hepatectomy [15]. It has been shown that sequential selective transarterial chemoembolization (TACE) before PVE increases the rate of hypertrophy $[15,16]$. In the event of inadequate FLR hypertrophy that precludes hepatectomy, this combined vascular obstruction of the tumor territory represents an efficient treatment of HCC. Another means of anticipating postoperative liver failure is to estimate the FLR volume in terms of proportional body weight, body surface area, and total liver volume (TLV) $[17,18]$ or by considering the hypertrophy rate of the FLR/TLV ratio [19] and several cutoff values, presuming that the underlying parenchyma has been established.

\section{Assessment of Liver Function}

The aim of preoperative assessment of liver function is to prevent posthepatectomy liver failure, which is the predominant cause of death in cirrhotic patients. The liver is characterized by its ability to regenerate but also by its capacity to ensure apparent normal liver function with a reduced functional volume. Predictive assessment of the postoperative functionality of a reduced-volume FLR and its capacity to regenerate is difficult. Because there are no valuable stress tests to assess the potential of liver function, preoperative assessment in patients with diseased parenchyma involves joint interpretation of several biological, morphological, histological, and hemodynamic factors. One method of biological assessment is the Child-Pugh classification [20], which was originally designed for predicting the prognosis of patients with portal hypertension undergoing shunting operations. Resection is contraindicated in grade $C$ cirrhotic patients and restricted to very limited resection in grade B cirrhotic patients [21]. However, even in grade A cirrhotic patients with apparently normal liver function, the risk of liver surgery is increased, necessitating the development of more sophisticated quantitative liver function tests. Among the various methods available, such as the monoethylglycinexylidide test and the galactose elimination capacity, the indocyanine green (ICG) clearance rate represents the most common test for predicting mortality after hepatectomy [22, 23]. After injection of $0.5 \mathrm{mg}$ of ICG per kilogram, its retention is measured in the peripheral blood at definite time points (usually after $15 \mathrm{~min}$; ICG-R15). The normal ICG value in healthy patients is approximately $10 \%$, and cutoff values predictive of safe major hepatectomies range from 14 to $17 \%$ [24, 25]. Minor resections can be performed for values up to $22 \%$ [26], limited hepatectomies for values up to $40 \%$ [23], and limited wedge laparoscopic resections, in the opinion of some researchers, can be tolerated for even higher values [27]. The Model for EndStage Liver Disease (MELD) score was validated as an accurate predictor of survival among different populations of patients with advanced liver disease $[28,29]$. In the case of LR, the impact of the MELD score was only studied retrospectively in some series of cirrhotic patients who had undergone LR for HCC. In two series of cirrhotic patients who underwent LR for HCC, 
the authors showed that a MELD score $>8$ was associated with a higher risk of mortality, morbidity, and impaired long-term survival $[28,29]$.

\section{Rationale of Anatomical Resection}

The anatomical territory of HCC ranges from subsegment to lobe according to the size of the tumor. Intrahepatic metastasis of HCC along the portal vein and the presence of satellite nodules up to $2 \mathrm{~cm}$ in size [30] are the criteria for anatomical LR. Indeed, anatomical resections according to the architecture of the portal vein have the potential to remove undetected cancerous foci (portal vein metastases and satellite nodules) disseminated from the primary gross tumor. Moreover, anatomical resections of small solitary HCCs achieve significantly better overall and disease-free survival than do limited resections, without increasing the postoperative risk [31-35]. However, the benefit of segmental resection may only become apparent in tumors between 2 and $5 \mathrm{~cm}$. Below this size, the risk of dissemination is considered to be negligible with equivalent efficacy of local ablative therapy; beyond this size, majority of patients will already have macroscopic vascular invasion or satellite nodules that lead to a high incidence of recurrence [36]. In the case of central tumors with undefined vascular territory, some authors have found lower recurrence rates and greater survival with 2-cm surgical margins compared with 1-cm margins [37]; however, other authors have found no difference between margins $<1$ or $>1 \mathrm{~cm}[33,38]$. A wide margin up to $2 \mathrm{~cm}$ is indeed required. Three-dimensional computed tomography (CT) computer-assisted preoperative surgical planning allows determination of resectability and changes in operative strategy (resection modifications/extensions/intrahepatic vascular reconstructions studying portal distribution, hepatic vein anatomy for adequate venous drainage, biliary distribution for avoiding biliary fistula) [39]. This preoperative assessment seems particularly helpful in patients with unconventional resection planes and in those with central tumors. In particular, it allows accurate determination of safely perfused/drained retained liver volumes.

\section{Results of Liver Resection}

The largest report of patients who have undergone resection comes from the Liver Cancer Study Group in Japan, which has reported 1-, 3-, 5-, and 10 year survival rates of 85, 64, 45 , and $21 \%$, respectively, in 6,785 cirrhotic patients treated by hepatic resection between 1988 and 1999 [40]. Comparable results have been reported by other groups worldwide without differences between Western and Asian studies. Survival rates as high as $60 \%$ at 5 years may be achieved in Child-Pugh grade A patients with well-encapsulated tumors of 2 -cm diameter. Although $<10 \%$ of patients fit these selection criteria, such results obtained in patients with good liver function who underwent anatomical resection could be favorably compared with those who underwent LT.

Recurrence after resection occurs in up to $80 \%$ of patients at 5 years [41]. An arbitrary 2 year cutoff has been raised to distinguish between early and late recurrence, with approximately two-thirds appearing in the first 2 years after treatment (early recurrence), which is considered a recurrence due to dissemination [42]. The factors related to early recurrence (tumor size, microvascular invasion, satellite nodules, $\alpha$-fetoprotein levels, nonanatomical resection) support this hypothesis. Other recurrences occur after 2 years (delayed recurrences) and may correspond to "de novo" tumors in the oncogenic cirrhotic liver [43]. The 
risk factors associated with delayed recurrence are presence of cirrhosis (F4), hepatitis activity, vascular invasion, moderate or poorly differentiated HCC, and multinodularity [42]. Recent genomic studies have proposed a molecular signature to define the level of risk due to oncogenicity of the cirrhotic liver [43], but this needs validation before entering clinical practice [44]. Several strategies have been tested to avoid recurrence, such as preoperative chemoembolization [45], chemotherapy, internal radiation [46], adoptive immunotherapy [47], retinoids [48], or interferon. Three meta-analyses have been published that assessed the utility of interferon in the prevention of recurrence after resection [49-51]. The results in all of the analyses favored the use of interferon, but the quality in most of the studies was low such that it is impossible to provide a robust recommendation. The efficacy of sorafenib in advanced stages has encouraged evaluation of this agent at earlier phases of the disease, but until data from the ongoing trials are available, there is no basis to recommend this agent to prevent recurrence. Any neoadjuvant or adjuvant therapy that can decrease or delay the incidence of intrahepatic recurrence should be considered after partial hepatectomy [52]. Despite the fact that TACE can, in some cases, downstage HCC, prospective trials have failed to show any significant benefit of this treatment before surgery [53-55]. Although recurrence following resection of HCC is associated with a poor outcome in most cases, there is growing evidence that some patients will benefit from more aggressive approaches, especially if the recurrence is limited to the liver $[56,57]$. Multimodality therapy of recurrence, including TACE, percutaneous ablative therapy, and re-resection could result in prolonged survival, with an overall 5 year survival rate of $20 \%$ [56].

\section{Liver Transplantation}

LT is the most popular therapeutic option for HCC because it removes both detectable and undetectable tumor nodules together with the preneoplastic lesions that are present in the cirrhotic liver. Moreover, it simultaneously treats the underlying cirrhosis and prevents the development of postoperative or distant complications associated with portal hypertension and liver failure. LT is not limited by liver function impairment, and in selected patients with limited tumors, survival is similar to LT for other indications with a low recurrence rate [4, 58]. However, it became apparent that the success of LT depends on the tumor load; patients with extensive disease had very poor outcomes, whereas most patients with small tumors could be cured. This led to many controversies concerning the use of LT in patients with HCC, such as the selection of patients in the context of organ shortage, control of the tumor load while patients wait for a graft, use of living donors, and the choice of immunosuppressive or adjuvant therapies [59]. An international consensus conference was recently held in Zurich, Switzerland with the aim of reviewing the current practice of LT in patients with HCC and to develop internationally accepted statements and guidelines [60].

\section{Criteria for Listing Candidates}

LT achieves excellent results in patients with limited tumors. Patients with HCC within the Milan criteria (MC; solitary HCC of $<5 \mathrm{~cm}$ or with up to three nodules of $<3 \mathrm{~cm}$ ) have a 5 year survival of $70 \%$ after LT with recurrence in less than $10 \%$. This survival matches posttransplant survival of most other indications for LT. In a meta-analysis of 101 studies that assessed the effect of HCC staging in terms of the size and number of nodules on post-transplant recurrence and survival, Burroughs and colleagues [61] concluded that assessment of the diameter of the largest nodule or total diameter of nodules was the best predictor of the outcome. After its introduction, the MC set restrictive limits for the size and the number of 
tumors in candidates for LT [62]. Mazzaferro et al. [63] recently showed that the MC is an independent prognostic factor for outcome after LT, representing the benchmark for selection of LT for HCC developed in cirrhosis. As evidence suggests good outcomes in some patients outside the MC, there has been a trend toward expansion of the criteria for LT. Only the University of California at San Francisco criteria (one tumor $\leq 6.5 \mathrm{~cm}$, three nodules at most with the largest $\leq 4.5 \mathrm{~cm}$, and total tumor diameter $\leq 8 \mathrm{~cm}$ ) have been prospectively validated [64]. Therefore, the International Consensus Conference on Liver Transplantation for HCC recommends a modest expansion of the number of potential candidates that may be considered on the basis of several studies that have shown comparable survival for patients outside the MC [60].

\section{Criteria of Liver Transplantation for Hepatocellular Carcinoma Candidates with Noncir- rhotic Livers}

Although most HCC occurs in patients with liver cirrhosis, approximately $10 \%$ of cases arise in noncirrhotic livers. In such patients, diagnosis is often made at an advanced stage, and LR is currently the preferred therapeutic option, when feasible, because patients with good liver reserve have high tolerance for extensive LR [65]. Nevertheless, in selected patients, salvage LT may be considered in cases of isolated intrahepatic recurrence with no evidence of macrovascular invasion or extrahepatic spread [60].

\section{Treatment on the Waiting List}

Increased waiting time is associated with tumor progression and especially development of vascular invasion. In the USA, approximately 7,000 new patients with HCC are put on the waiting list every year [66], 10-15\% of whom die during the waiting period [67]. In Europe, the dropout rate at various centers ranges between 15 and 35\% [68, 69]. Accordingly, strategies to increase the donor pool and diminish the tumor progression rate became a priority in many centers. In the USA, the United Network for Organ Sharing proposed a new system to allocate patients on the list according to the MELD score [70]. This change gives a priority to patients to decrease the dropout rate. Additional organs might be used by accepting marginal livers (advanced age or steatotic organs, nonheart beating, HCV infected) and domino or split LT, but this would have little impact. Living donor LT has emerged as the most feasible alternative to cadaveric LT. Increased benefits have been observed following living donor LT compared to cadaveric LT for early HCC in patients with waiting times exceeding 7 months [71]. The availability of living donor LT has opened the potential for an expansion of the criteria beyond those conventionally applied. However, it can be anticipated that a massive extension of the criteria for LT to patients with larger tumors may significantly impair the results of transplantation in general. Because the morbidity-mortality of the donor is a major concern, it is highly questionable to put a donor at risk for an uncertain recipient prognosis [72].

Tumor management while awaiting LT includes several modalities such as percutaneous radiofrequency ablation, TACE, and hepatic resection. The two nonsurgical treatments are widely used, but their impact on survival is unproven. We have demonstrated that surgical resection before LT does not increase the surgical risk nor impair survival [9]. Therefore, resection and transplantation could be associated rather than considered separately. Resection could be used as a bridge to transplantation, especially for tumors located in the upper part of the right liver, which can be easily and completely removed through a transthoracic incision. Similarly, some superficial tumors that are not easily accessible by a percutaneous approach could be resected through a laparoscopic approach.

Several studies have confirmed that LT for recurrence after LR did not increase the operative risk and offered a chance of long-term survival when HCC recurrence was limited 
Table 1. Risk factors for failure of a salvage liver transplantation strategy

\begin{tabular}{lllll}
\hline $\begin{array}{l}\text { Number of pejorative } \\
\text { histologic factors * }\end{array}$ & $\begin{array}{l}\text { Number of } \\
\text { patients } \\
\mathrm{n}=112\end{array}$ & $\begin{array}{l}\text { No recurrence } \\
\mathrm{n}=22\end{array}$ & $\begin{array}{l}\text { Recurrence } \\
\text { within MC } \\
\mathrm{n}=60\end{array}$ & $\begin{array}{l}\text { Recurrence } \\
\text { beyond MC } \\
\mathrm{n}=30\end{array}$ \\
\hline 0 & 41 & $10(24 \%)$ & $31(76 \%)$ & 0 \\
1 & 43 & $10(23 \%)$ & $24(56 \%)$ & $9(21 \%)$ \\
2 & 14 & $2(14 \%)$ & $5(36 \%)$ & $7(50 \%)$ \\
3 & 8 & 0 & 0 & $8(100 \%)$ \\
$4-5$ & 6 & 0 & 0 & $6(100 \%)$ \\
\hline
\end{tabular}

* Pejorative histological factors: tumor size $>3 \mathrm{~cm}$, poorly differentiated, vascular invasion, satellite nodules, and cirrhosis.

$[9,73,74]$. Initial LR of HCC as primary therapy in patients who otherwise could have been transplanted offers good quality of life and is less demanding than LT. Patients do not need long-term immunosuppression; in addition, grafts are saved for the community and can be transplanted to other patients with no alternative to LT [7, 9, 73]. For LR as primary therapy for tumor recurrence or deterioration in liver function, "salvage transplantation" was first proposed by Majno et al. [75] This attractive concept seems to be applicable in a significant proportion of patients with long-term survival similar to that of patients who undergo primary LT $[9,73,76]$.

However, salvage transplantation is restricted to patients who develop recurrence within the MC, which could be a lost opportunity for treatment of the subgroup of initially transplantable patients who develop recurrence outside the MC . In other words, the choice to delay LT should be applied to patients who (a) develop recurrence within the MC, (b) will adhere to a careful follow-up with imaging to detect early recurrence, and (c) still have a general condition comparable to that following LT. In an intention-to-treat study that performed LR for HCC first in patients with good liver function, we showed that initial LR in patients with good liver function was a valid treatment because the 5- and 10 year overall survival rates were similar to those of the group that underwent LT first. The most important result of this intention-totreat study was that approximately half of our patients with HCC recurrence following LR did not undergo transplantation, including one-third because of recurrence beyond the MC. This result is a matter of debate concerning the respective roles of LR and LT in the treatment of HCC $[7,73,76]$. Analysis of the subgroup of patients who could not undergo transplantation at the time of recurrence showed that three factors were associated with failure. These factors were respectively related to the patient, tumor, and underlying parenchyma. The first striking factor was related to patient adherence to regular follow-up during prolonged periods after LR. Approximately $20 \%$ of our patients who developed recurrence beyond the MC had suboptimal follow-up. This failure illustrates the need for a more stringent screening program with repeated abdominal CT scans or magnetic resonance imaging, similar to that used in patients on the waiting list before LT $[4,5,77]$. Therefore, we would be reluctant to propose this strategy for patients geographically distant from the tertiary center. Another important result of this intention-to-treat study was that approximately $15 \%$ of patients with recurrence within the MC did not undergo transplantation because they had grown too old or had developed severe comorbidities at the time of recurrence, which appears to be an unavoidable conse- 


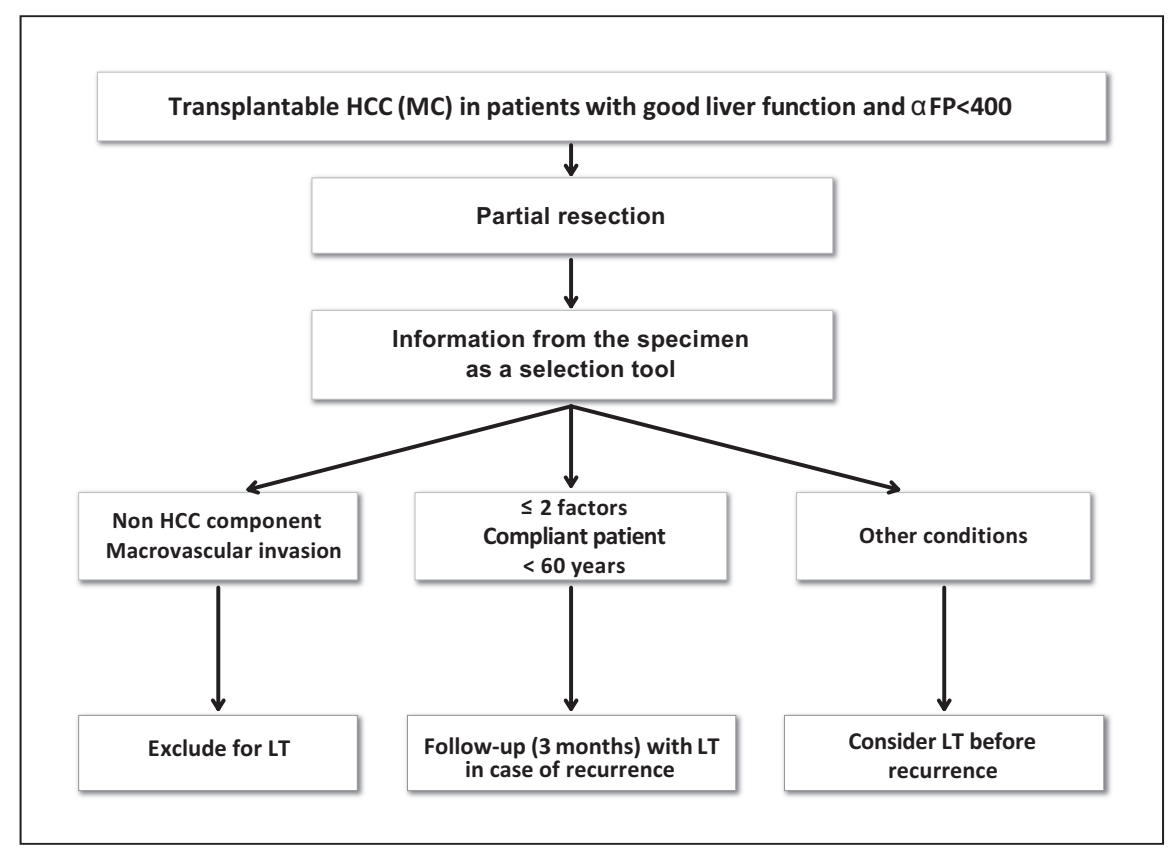

Fig. 1. Proposed decision tree using specimen analysis after initial LR in transplantable patients with good liver function.

quence of the improvement of life expectancy after LR [7, 76, 77]. Prediction of recurrence after LR depends on tumor aggression, which can be assessed by pathological data. Sala et al. first proposed performing LT after LR in patients with a high histological risk of recurrence [78]. Our study provides support for substantial arguments for a selection process based on analysis of specimens. The presence of very pejorative factors, including vascular invasion in subsegmental portal veins not detected on standard imaging and specific cholangiocarcinoma components, which are more often discovered [79], should indicate patients who need LT. Among pejorative histological factors, we found that patients with three or more factors were at a very high risk of recurrence beyond the MC (table 1). This selection analysis gives solid arguments for considering LT before recurrence. Prediction of recurrence after LR also depends on the liver carcinogenic field. Cirrhosis was present in the vast majority of our patients with recurrence beyond the MC, emphasizing the preneoplastic status of the underlying liver disease [80,81]. Recurrences that can be attributed to de novo cancers may be prevented by treating the cause of the underlying liver disease $[82,83]$. However, to what extent antiviral therapy has had a significant impact on reducing recurrence following resection is still a matter of debate [84, 85].

In conclusion, an increasing body of evidence has shown that initial LR of transplantable patients within the MC who have good liver function is a valid option. Furthermore, histological analysis of specimens allows a valid selection of the subgroup of patients who could benefit from follow-up with LT in case of recurrence, and conversely, consideration of LT before recurrence in patients with multiple pejorative histological factors [9] (fig. 1). 


\section{References}

1 Ferlay J, Shin HR, Bray F, Forman D, Mathers C, Parkin DM: Estimates of worldwide burden of cancer in 2008: GLOBOCAN 2008. Int J Cancer 2010;127:2893-2917.

2 Rahbari NN, Mehrabi A, Mollberg NM, Müller SA, Koch M, Büchler MW, Weitz J: Hepatocellular carcinoma: current management and perspectives for the future. Ann Surg 2011;253:453-469.

3 El-Serag HB, Marrero JA, Rudolph L, Reddy KR: Diagnosis and treatment of hepatocellular carcinoma. Gastroenterology 2008;134:1752-1763.

4 Llovet JM, Burroughs A, Bruix J: Hepatocellular carcinoma. Lancet 2003;362:1907-1917.

5 Forner A, Reig ME, de Lope CR, Bruix J: Current strategy for staging and treatment: the BCLC update and future prospects. Semin Liver Dis 2010;30:61-74.

6 Eguchi S, Kanematsu T, Arii S, Liver Cancer Study Group of Japan: Recurrence-free survival more than 10 years after liver resection for hepatocellular carcinoma. Br J Surg 2011;98:552-557.

7 Cucchetti A, Vitale A, Gaudio MD, Pinna AD: Harm and benefits of primary liver resection and salvage transplantation for hepatocellular carcinoma. Am J Transplant 2010;10:619-627.

8 Fuks D, Dokmak S, Paradis V, Diouf M, Durand F, Belghiti J: Benefit of initial resection of hepatocellular carcinoma followed by transplantation in case of recurrence: An intention-to-treat analysis. Hepatology 2012;55:132-140.

9 Belghiti J, Cortes A, Abdalla EK, Regimbeau JM, Prakash K, Durand F, et al: Resection prior to liver transplantation for hepatocellular carcinoma. Ann Surg 2003;238:885-892.

10 Poon RT, Fan ST, Lo CM, Liu CL, Wong J: Long-term survival and pattern of recurrence after resection of small hepatocellular carcinoma in patients with preserved liver function: implications for a strategy of salvage transplantation. Ann Surg 2002;235:373-382.

11 Ishizawa T, Hasegawa K, Aoki T, Takahashi M, Inoue Y, Sano K, Imamura H, Sugawara Y, Kokudo N, Makuuchi M: Neither multiple tumors nor portal hypertension are surgical contraindications for hepatocellular carcinoma. Gastroenterology 2008;134:1908-1916.

12 Makuuchi M, Sano K: The surgical approach to HCC: our progress and results in Japan. Liver Transpl 2004;10:S46-S52.

13 Farges O, Malassagne B, Flejou JF, Balzan S, Sauvanet A, Belghiti J: Risk of major liver resection in patients with underlying chronic liver disease: a reappraisal. Ann Surg 1999;229:210-215.

14 Yamakado K, Takeda K, Matsumura K, Nakatsuka A, Hirano T, Kato N, et al: Regeneration of the un-embolized liver parenchyma following portal vein embolization. J Hepatol 1997;27:871-880.

15 Ogata S, Belghiti J, Farges O, Varma D, Sibert A, Vilgrain V: Sequential arterial and portal vein embolizations before right hepatectomy in patients with cirrhosis and hepatocellular carcinoma. Br J Surg 2006;93:10911098.

16 Yoo H, Kim JH, Ko GY, Kim KW, Gwon DI, Lee SG, Hwang S: Sequential transcatheter arterial chemoembolization and portal vein embolization versus portal vein embolization only before major hepatectomy for patients with hepatocellular carcinoma. Ann Surg Oncol 2011;18:1251-1257.

17 Truant S, Oberlin 0, Sregent G, et al: Remnant liver volume to body weight ratio>or 00.5\%: A new cutoff to estimate postoperative risks after extended liver resection in noncirrhotic liver. J Am Coll Surg 2007;204:22-33.

18 Chun YS, Ribero D, Abdala EK, et al: Comparison of two methods of future liver remnant volume measurement. J Gastrointest Surg 2008;12:123-128.

19 Farges 0, Belghiti J, Kianmanesh R, et al: Portal vein embolization before right hepatectomy: Prospective clinical trial. Ann Surg 2003;237:208-217.

20 Pugh RN, Murray-Lyon IM, Dawson JL, Pietroni MC, Williams R: Transection of the oesophagus for bleeding oesophageal varices. Br J Surg 1973;60:646-649.

21 Belghiti J, Regimbeau JM, Durand F, Kianmanesh AR, Dondero F, Terris B, et al: Resection of hepatocellular carcinoma: a European experience on 328 cases. Hepatogastroenterology 2002;49:41-46.

22 Torzilli G, Makuuchi M, InoueK, Takayama T, Sakamoto Y, Sugawara Y, Kubota K, Zucchi A: No-mortality liver resection for hepatocellular carcinoma in cirrhotic and noncirrhotic patients: is there a way? A prospective analysis of our approach. Arch Surg 1999;134:984-992.

23 Wakabayashi H, Ishimura K, Izuishi K, Karasawa Y, Maeta H: Evaluation of liver function for hepatic resection for hepatocellular carcinoma in the liver with damaged parenchyma. J Surg Res 2004;116:248-252.

24 Fan ST, Lai EC, Lo CM, et al: Hospital mortality of major hepatectomy for hepatocellular carcinoma associated with cirrhosis. Arch Surg 1995;130:198-203.

25 Lam CM, Fan ST, Lo CM, et al: Major hepatectomy for hepatocellular carcinoma in patients with an unsatisfactory indocyanine green clearance test. Br J Surg 1999;86:1012-1017.

26 FanST: Liver functional reserve estimation: state of the art and relevance for local treatments: the Eastern perspective. J Hepatobiliary Pancreat Sci 2010;17:380-384.

27 Belli G, Fantini C, Belli A, Limongelli P: Laparoscopic liver resection for hepatocellular carcinoma in cirrhosis: longterm outcomes. Dig Surg 2011;28:134-140.

28 Hsu KY, Chau GY, Lui WY, Tsay SH, King KL, Wu CW: Predicting morbidity and mortality after hepatic resection in patients with hepatocellular carcinoma: the role of Model for End-Stage Liver Disease score. World J Surg 2009;33:2412-2419.

29 Delis SG, Bakoyiannis A, Biliatis I, Athanassiou K, Tassopoulos N, Dervenis C: Model for end-stage liver disease (MELD) score, as a prognostic factor for post-operative morbidity and mortality in cirrhotic patients, undergoing hepatectomy for hepatocellular carcinoma. HPB (Oxford) 2009;11:351-357. 
30 Roayaie S, Blume IN, Thung SN, Guido M, Fiel MI, Hiotis S, et al: A system of classifying microvascular invasion to predict outcome after resection in patients with hepatocellular carcinoma. Gastroenterology 2009;137:850-855.

31 Imamura H, Matsuyama Y, Miyagawa Y, Ishida K, Shimada R, Miyagawa S, et al: Prognostic significance of anatomical resection and des-gamma-carboxy prothrombin in patients with hepatocellular carcinoma. Br J Surg 1999;86:1032-1038.

32 Regimbeau JM, Kianmanesh R, Farges O, Dondero F, Sauvanet A, Belghiti J: Extent of liver resection influences the outcome in patients with cirrhosis and small hepatocellular carcinoma. Surgery 2002;131:311317.

33 Arii S, Tanaka S, Mitsunori Y, Nakamura N, Kudo A, Noguchi N, Irie T: Surgical strategies for hepatocellular carcinoma with special reference to anatomical hepatic resection and intraoperative contrast-enhanced ultrasonography. Oncology 2010;78(Suppl 1):125-130.

34 Eguchi S, Kanematsu T, Arii S, Okazaki M, Okita K, Omata M, Ikai I, Kudo M, Kojiro M, Makuuchi M, Monden M, Matsuyama Y, Nakanuma Y, Takayasu K, Liver Cancer Study Group of Japan: Comparison of the outcomes between an anatomical subsegmentectomy and a non-anatomical minor hepatectomy for single hepatocellular carcinomas based on a Japanese nationwide survey. Surgery 2008;143:469-475.

35 Wakai T, Shirai Y, Sakata J, Kaneko K, Cruz PV, Akazawa K, Hatakeyama K: Anatomic resection independently improves long-term survival in patients with T1-T2 hepatocellular carcinoma. Ann Surg Oncol 2007;14:1356-1365.

36 Ueno S, Kubo F, Sakoda M, Hiwatashi K, Tateno T, Mataki Y, Maemura K, Shinchi H, Natsugoe S, Aikou T: Efficacy of anatomic resection vs nonanatomic resection for small nodular hepatocellular carcinoma based on gross classification. J Hepatobiliary Pancreat Surg 2008;15:493-500.

37 Shi M, Guo RP, Lin XJ, et al: Partial hepatectomy with wide versus narrow resection margin for solitary hepatocellular carcinoma: a prospective randomized trial. Ann Surg 2007;245:36-43.

38 Poon RT, Fan ST, Ng IO, Lo CM, Liu CL, Wong J: Different risk factors and prognosis for early and late intrahepatic recurrence after resection of hepatocellular carcinoma. Cancer 2000;89:500-507.

39 Radtke A, Sotiropoulos GC, Molmenti EP, Schroeder T, Peitgen HO, Frilling A, Broering DC, Broelsch CE, Malago M: Computer-assisted surgery planning for complex liver resections: when is it helpful? A singlecenter experience over an 8-year period. Ann Surg 2010;252:876-883.

40 Ikai I, Itai Y, Okita K, Omata M, Kojiro M, Kobayashi K, et al: Report of the 15th follow-up survey of primary liver cancer. Hepatol Res 2004;28:21-29.

41 Cha CH, Ruo L, Fong Y, Jarnagin WR, Shia J, Blumgart LH, et al: Resection of hepatocellular carcinoma in patients otherwise eligible for transplantation. Ann Surg 2003;238:315-321.

42 Imamura H, Matsuyama Y, Tanaka E, Ohkubo T, Hasegawa K, Miyagawa S, et al: Risk factors contributing to early and late phase intrahepatic recurrence of hepatocellular carcinoma after hepatectomy. J Hepatol 2003;38:200-207.

43 Hoshida Y, Villanueva A, Kobayashi M, Peix J, Chiang DY, Camargo A, Gupta S, Moore J, Wrobel MJ, Lerner J, Reich M, Chan JA, Glickman JN, Ikeda K, Hashimoto M, Watanabe G, Daidone MG, Roayaie S, Schwartz M, Thung S, Salvesen HB, Gabriel S, Mazzaferro V, Bruix J, Friedman SL, Kumada H, Llovet JM, Golub TR: Gene expression in fixed tissues and outcome in hepatocellular carcinoma. N Engl J Med 2008;359:1995-2004.

44 Subramanian J, Simon R: What should physicians look for in evaluating prognostic gene-expression signatures? Nat Rev Clin Oncol 2010;7:327-334.

45 Zhou WP, Lai EC, Li AJ, Fu SY, Zhou JP, Pan ZY, Lau WY, Wu MC: A prospective, randomized, controlled trial of preoperative transarterial chemoembolization for resectable large hepatocellular carcinoma. Ann Surg 2009;249:195-202.

46 Lau WY, Leung TW, Ho SK, Chan M, Machin D, Lau J, Chan AT, Yeo W, Mok TS, Yu SC, Leung NW, Johnson PJ: Adjuvant intra-arterial iodine-131-labelled lipiodol for resectable hepatocellular carcinoma: a prospective randomised trial. Lancet 1999;353:797-801.

47 Takayama T, Sekine T, Makuuchi M, Yamasaki S, Kosuge T, Yamamoto J, Shimada K, Sakamoto M, Hirohashi S, Ohashi Y, Kakizoe T: Adoptive immunotherapy to lower postsurgical recurrence rates of hepatocellular carcinoma: a randomised trial. Lancet 2000;356:802-807.

48 Muto Y, Moriwaki H, Ninomiya M, Adachi S, Saito A, Takasaki KT, Tanaka T, Tsurumi K, Okuno M, Tomita E, Nakamura T, Kojima T: Prevention of second primary tumors by an acyclic retinoid, polyprenoic acid, in patients with hepatocellular carcinoma. Hepatoma Prevention Study Group. N Engl J Med 1996;334:15611567.

49 Breitenstein S, Dimitroulis D, Petrowsky H, Puhan MA, Müllhaupt B, Clavien PA: Systematic review and meta-analysis of interferon after curative treatment of hepatocellular carcinoma in patients with viral hepatitis. Br J Surg 2009;96:975-981.

50 Miyake Y, Takaki A, Iwasaki Y, Yamamoto K: Metaanalysis: interferon-alpha prevents the recurrence after curative treatment of hepatitis C virus-related hepatocellular carcinoma. J Viral Hepat 2010;17:287-292.

51 Shen YC, Hsu C, Chen LT, Cheng CC, Hu FC, Cheng AL: Adjuvant interferon therapy after curative therapy for hepatocellular carcinoma (HCC): a meta-regression approach. J Hepatol 2010;52:889-894.

52 Lau WY: Management of hepatocellular carcinoma. J R Coll Surg Edinb 2002;47:389-399.

53 Luo YQ, Wang Y, Chen H, Wu MC: Influence of preoperative transcatheter arterial chemoembolization on liver resection in patients with resectable hepatocellular carcinoma. Hepatobiliary Pancreat Dis Int 2002;1:523-526. 
54 Majno PE, Adam R, Bismuth H, Castaing D, Ariche A, Krissat J, et al: Influence of preoperative transarterial lipiodol chemoembolization on resection and transplantation for hepatocellular carcinoma in patients with cirrhosis. Ann Surg 1997;226:688-701.

55 Schwartz JD, Schwartz M, Mandeli J, Sung M: Neoadjuvant and adjuvant therapy for resectable hepatocellular carcinoma: review of the randomised clinical trials. Lancet Oncol 2002;3:593-603.

56 Poon RT, Fan ST, O'Suilleabhain CB, Wong J: Aggressive management of patients with extrahepatic and intrahepatic recurrences of hepatocellular carcinoma by combined resection and locoregional therapy. J Am Coll Surg 2002;195:311-318.

57 Minagawa M, Makuuchi M, Takayama T, Kokudo N: Selection criteria for repeat hepatectomy in patients with recurrent hepatocellular carcinoma. Ann Surg 2003;238:703-710.

58 Bruix J, Sherman M: Management of hepatocellular carcinoma. Hepatology 2005;42:1208-1236.

59 Bruix J, Sherman M: Management of hepatocellular carcinoma: an update. Hepatology 2011;53:1020-1022.

60 Clavien PA, Lesurtel M, Bossuyt PM, Gores GJ, Langer B, Perrier A, OLT for HCC Consensus Group: Recommendations for liver transplantation for hepatocellular carcinoma: an international consensus conference report. Lancet Oncol 2012;13:e11-e22.

61 Germani G, Gurusamy K, Garcovich M, Toso C, Fede G, Hemming A, Suh KS, Weber A, Burroughs AK: Which matters most: number of tumors, size of the largest tumor, or total tumor volume? Liver Transpl 2011;17(Suppl 2):S58-S66.

62 Mazzaferro V, Regalia E, Doci R, Andreola S, Pulvirenti A, Bozzetti F, et al: Liver transplantation for the treatment of small hepatocellular carcinomas in patients with cirrhosis. N Engl J Med 1996;334:693-699.

63 Mazzaferro V, Bhoori S, Sposito C, Bongini M, Langer M, Miceli R, Mariani L: Milan criteria in liver transplantation for hepatocellular carcinoma: an evidence-based analysis of 15 years of experience. Liver Transpl 2011;17:S44-S57.

64 Yao FY, Xiao L, Bass NM, et al: Liver transplantation for hepatocellular carcinoma: validation of the UCSFexpanded criteria based on preoperative imaging. Am J Transplant 2007;7:2587-2596.

65 Clavien PA, Petrowsky H, DeOliveira ML, et al: Strategies for safer liver surgery and partial liver transplantation. N Engl J Med 2007;356:1545-1559.

66 Axelrod DA, Guidinger MK, Finlayson S, et al: Rates of solid-organ wait-listing, transplantation, and survival among residents of rural and urban areas. JAMA 2008;299:202-207.

67 Llovet JM, Fuster J, Bruix J: Intention-to-treat analysis of surgical treatment for early hepatocellular carcinoma: resection versus transplantation. Hepatology 1999;30:1434-1440.

68 Ratcliffe J, Young T, Buxton M, Eldabi T, Paul R, Burroughs A, Papatheodoridis G, Rolles K: A simulation modelling approach to evaluating alternative policies for the management of the waiting list for liver transplantation. Health Care Manag Sci 2001;4:117-124.

69 Foxton MR, Al-Freah MA, Portal AJ, et al: Increased model for end-stage liver disease score at the time of liver transplant results in prolonged hospitalization and overall intensive care unit costs. Liver Transpl 2010;16:668-677.

70 Saab S, Wang V, Ibrahim AB, Durazo F, Han S, Farmer DG, et al: MELD score predicts 1-year patient survival post or thotopic liver transplantation. Liver Transpl 2003;9:473-476.

71 Sarasin FP, Majno PE, Llovet JM, Bruix J, Mentha G, Hadengue A: Living donor liver transplantation for early hepatocellular carcinoma: a life-expectancy and cost-effectiveness perspective. Hepatology 2001;33:10731079.

72 StrongRW: Whither living donor liver transplantation? Liver Transpl Surg 1999;5:536-538.

73 Cherqui D, Laurent A, Mocellin N, Tayar C, Luciani A, Nhieu V, et al: Liver resection for transplantable hepatocellular carcinoma: long-term survival and role of secondary liver transplantation. Ann Surg 2009;250:738-746.

74 Poon RT, Fan ST, Lo CM, Liu CL, Wong J: Difference in tumor invasiveness in cirrhotic patients with hepatocellular carcinoma fulfilling the Milan criteria treated by resection and transplantation: impact on longterm survival. Ann Surg 2007;245:51-58.

75 Majno PE, Sarasin FP, Mentha G, Hadengue A: Primary liver resection and salvage transplantation or primary liver transplantation in patients with single, small hepatocellular carcinoma and preserved liver function: an outcome-oriented decision analysis. Hepatology 2000;31:899-906.

76 Del Gaudio M, Ercolani G, Ravaioli M, Cescon M, Lauro A, Vivarelli M, Zanello M, Cucchetti A, Vetrone G, Tuci F, Ramacciato G, Grazi GL, Pinna AD: Liver transplantation for recurrent hepatocellular carcinoma on cirrhosis after liver resection: University of Bologna experience. Am J Transplant 2008;8:1177-1185.

77 Belghiti J, Carr BI, Greig PD, Lencioni R, Poon RT: Treatment before liver transplantation for HCC. Ann Surg Oncol 2008;15:993-1000.

78 Sala M, Fuster J, Llovet JM, Navasa M, Soli M, Varela M, et al: High pathological risk of recurrence after surgical resection for hepatocellular carcinoma: an indication for salvage liver transplantation. Liver Transpl 2004;10:1294-1300.

79 Sapisochin G, Fidelman N, Roberts JP, Yao FY: Mixed hepatocellular cholangiocarcinoma and intrahepatic choangiocarcinoma in patients undergoing transplantation for hepatocellular carcinoma. Liver Transpl 2011;17:934-942.

80 Hoshida Y: Risk of recurrence in hepatitis B-related hepatocellular carcinoma: impact of viral load in late recurrence. J Hepatol 2009;51:842-844.

81 Saneto H, Kobayashi M, Kawamura Y, Yatsuji H, Sezaki H, Hosaka T, et al: Clinicopathological features, background liver disease, and survival analysis of HCV-positive patients with hepatocellular carcinoma: differences between young and elderly patients. J Gastroenterol 2008;43:975-981. 
82 Tsuchiya M, Parker JS, Kono H, Matsuda M, Fuji H, Rusyn I: Gene expression in nontumoral liver tissue and recurrence-free survival in hepatitis C virus-positive hepatocellular carcinoma. Mol Cancer 2010;9:74.

83 Dienstag JL, Ghany MG, Morgan TR, Di Biscegli AM, Bonkovsky HL, Kim HY, HALT-C Trial Group: A prospective study of the rate of progression in compensated, histologically advanced chronic hepatitis $\mathrm{C}$ (HEP-10-2210). Hepatology 2011;54:396-405.

84 Berenguer M, Palau A, Aguilera V, Benlloch S, Aguilera V, Prieto M, et al: Clinical benefits of antiviral therapy in patients with recurrent hepatitis C following liver transplantation. Am J Transplant 2008;8:679687.

85 Carrión JA, Navasa M, García-Retortillo M, García-Pagan JC, Crespo G, Briguera M, Bosch J, Forns X: Efficacy of antiviral therapy on hepatitis $C$ recurrence after liver transplantation: a randomized controlled study. Gastroenterology 2007;132:1746-1756. 